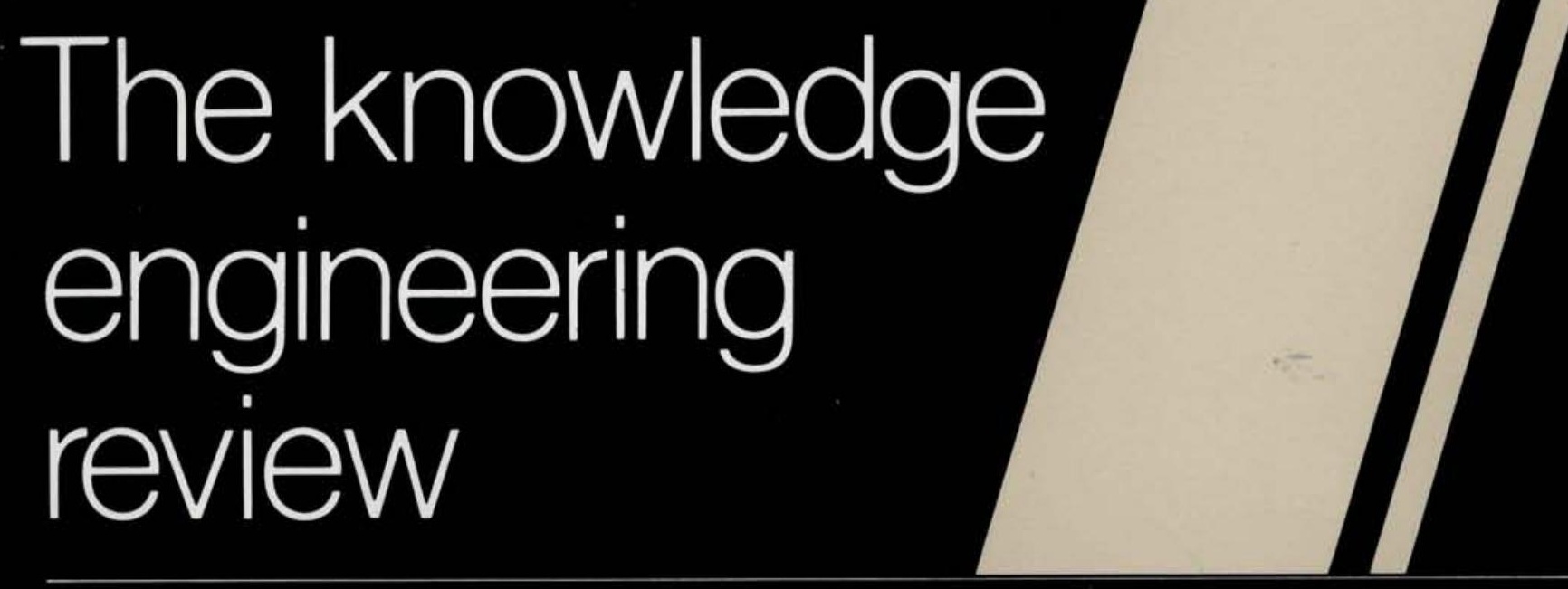

VOLUME 7 NUMBER 4 DECEMBER 1992

Cambridge University Pre 


\section{The knowledge engineering review}

EDITOR

Dr John Fox, Imperial Cancer Research Fund, London

NORTH AMERICAN EDITOR

Dr Peter Jackson, Clarkson University, USA

EDITORIAL BOARD

Alain Bonnet

Ecole Nationale, France

D. Navin Chandra

Carnegie Mellon University, USA

Dominic Clark

W. Clancey

Paul Cohen

R. Davis

Imperial Cancer Research Fund, UK

Mark Drummond

Institute for Research on Learning, USA

University of Massachusetts, USA

Massachusetts Institute of Technology, USA

Peter Friedland

Dov Gabbay

Sture Hägglund

Peter Hammond

Steve Laufmann

J. P. Laurent

Rainer Manthey

Elaine Rich

N. Shadbolt

Bill Sharpe

Barry Silverman

Madan Singh

Luc Steels

NASA Ames Research Center, USA

NASA Ames Research Center, USA

Imperial College, UK

Linköping University, Sweden

Imperial Cancer Research Fund, UK

US WEST Advanced Technologies, USA

University of Savoy, France

European Computer Industry Research Centre, Germany

Microelectronics and Computer Corporation, USA

University of Nottingham, UK

Hewlett Packard Labs, UK

The George Washington University, USA

University of Manchester, UK

Free University of Brussels, Belgium

Masons, Solicitors, UK

Richard Susskind

Austin Tate

University of Edinburgh Al Applications Institute, $U K$

Michael Wellman

University of Michigan, USA

\section{The Knowledge Engineering Review: Publication Policy}

The Knowledge Engineering Review has been established to provide a general source of information and analysis in all areas relevant to research and development in knowledge based systems and applied artificial intelligence. The editors wish to encourage careful preparation of original papers analysing developments in the field. In particular we wish to see tutorial and survey articles, and commentary, criticism and debate. Primary research papers on specialised technical topics are unlikely to be appropriate but research papers on broad topics, such as development methodology or general evaluations of tools and techniques, are of interest. Descriptions of specific projects or particular computer systems will be considered if their presentation draws out general issues in the design, implementation or impact of knowledge based systems.

\section{(C) Cambridge University Press 1992}

\section{Copying}

This journal is registered with the Copyright Center, 27 Congress St., Salem, Mass. 01970. Organisations in the USA are also registered with C.C.C. may therefore copy material (beyond the limits permitted by sections 107 and 108 of US copyright law) subject to payment to C.C.C. of the per-copy fee of $\$ 05.00$. This consent does not extend to multiple copy for promotional or commercial purposes. Code 0269-8889/92 $\$ 5.00+.00$.

FOR ALL OTHER USE, permission should be sought from the Cambridge or New York offices of the Cambridge University Press.

THE KNOWLEDGE ENGINEERING REVIEW (ISSN 0269-8889) is published every three months in March, June, September and December. Four parts form a volume.

ORDERS, which must be accompanied by payment, should be sent to any bookseller or subscription agent, or direct to Cambridge University Press, The Edinburgh Building, Shaftesbury Road, Cambridge CB2 2RU. Subscriptions in the USA or Canada should be sent to Cambridge University Press, 40 West 20th Street, New York, NY 10011-4211. The subscription price of volume 7, 1992 is $£ 69.00$ (US\$129.00 in the USA and Canada) for institutions; $£ 40.00$ (US\$65 in the USA and Canada) for individuals; including postage; separate parts cost $£ 18.00$ (US $\$ 34.00$ in the USA and Canada) plus postage. Second class postage paid at New York, NY, and at additional mailing offices. POSTMASTER: send address changes in USA and Canada to The Knowledge Engineering Review, Cambridge University Press, 110 Midland Avenue, Port Chester, New York, NY 105739864.

CLAIMS for missing issues can only be considered if made immediately after receipt of the subsequent issue. BACK vOLUMES: Volumes 1-6 are available from Cambridge University Press.

ADVERTISING: Details of advertising in The Knowledge Engineering Review may be obtained from the publisher https://doi.org/10.1017/S026988890000641X Published online by Cambridge University Press 